\title{
Insoluble Fiber Is a Major Constituent Responsible for Lowering the Post- Prandial Blood Glucose Concentration in the Pre-Germinated Brown Rice
}

\author{
Taiichiro Seki, ${ }^{*, a}$ Ryohei Nagase, ${ }^{a}$ Mariko Torimitsu, ${ }^{a}$ Megumi Yanagi,${ }^{a}$ Yukihiko Ito, ${ }^{b}$ \\ Mitsuo Kise, ${ }^{b}$ Aya Mizukuchi, ${ }^{b}$ Naoko Fujimura,${ }^{b}$ Kohusuke Hayamizu, ${ }^{b}$ and Toyohiko Ariga ${ }^{a}$ \\ ${ }^{a}$ Department of Agricultural and Biological Chemistry, Nihon University College of Bioresouce Sciences; 1866 Kameino, \\ Fujisawa, Kanagawa 252-8510, Japan: and ${ }^{b}$ Central Research Laboratory, FANCL Corporation; 12-13 Kamishinano, \\ Totsuka-ku, Yokohama, Kanagawa 244-0806, Japan. Received February 19, 2005; accepted May 12, 2005
}

The intake of pre-germinated brown rice (PR) instead of white rice (WR) ameliorates the hyperglycemia. To clarify the mechanism(s) to decrease the post-prandial blood glucose concentration, the effect of watersoluble/oil-soluble fraction-depleted PR bran (termed as "DB"; which is destarched and defatted PR bran) on post-prandial blood glucose was compared with that of full-fat PR bran (PB) or WR. The test diets, WR diet, PB diet and DB diet which are containing identical amount of available carbohydrate $(1.5 \mathrm{~g})$ were fed to Wistar strain rats. Post-prandial blood glucose concentration and incremental area under the curve (IAUC) for DB diet were lower than those for WR diet, and there was no difference between the DB diet and PB diet. Changes in plasma insulin concentration and the IAUC obtained also revealed the same tendency as those observed in blood glucose concentration. These results indicate that the blood glucose-lowering effect of $P B$ diet may be derived from the properties of $P B$ involving substantially higher content of dietary fiber than WR, and that the potential benefit of intake of PR instead of WR in the prevention of diabetic vascular complications.

Key words pre-germinated brown rice; white rice; dietary fiber; glycemic index; diabetes

Pre-germinated brown rice (PR) has recently been widely served in Japan. PR has been developed industrially in order to enhance the nutritional functions of its source material, brown rice (BR). PR is produced by soaking BR in water for slight germination. Amounts of some constituents including $\gamma$-aminobutyric acid (GABA) are remarkably increased in PR. GABA is also known to potentiate the insulin secretion in pancreas. ${ }^{1-4)}$

Thus PR is thought to ameliorate the disorders such as diabetes, although there is little scientific evidence regarding nutritional function of BR.

We have reported that the feeding of PR diet to streptozotocin-induced type 1 diabetic rats ameliorated the elevation of blood glucose, type-1 plasminogen activator inhibitor (PAI-1) and lipid peroxide concentrations in comparison with rats fed white rice (WR) diet. ${ }^{5)}$ These results suggest that intake of PR instead of WR is effective for the prevention of diabetic vascular complications including macrovascular complications such as myocardial infarction ${ }^{6,7)}$ and microvascular complications, retinopathy and nephropathy. ${ }^{6,8)}$ It has been reported that the glycemic index (GI) obtained from volunteers who took PR was significantly lower than that of those who were taking WR, however, there was no significant difference between the groups PR and BR. ${ }^{9)}$ These results suggest that the PR-specific component which is found only in PR would not be involved in the suppression of post prandial glucose levels, because PR and BR showed almost identical effect.

In the present study we tried to identify which component(s) in PR is responsible for these benefits to control the blood glucose levels by using destarched and defatted PR bran (DB) in an animal model. We now report that dietary fiber, but not GABA is a major active component responsible for the suppression of post-prandial glucose level.

\section{MATERIALS AND METHODS}

WR and PR used in this study were prepared from the same rice (short grain variety) produced in Hokkaido, Japan. PR manufactured using a patented method (Patent No. P3423931, JP, Jul. 7, 2003) was used. PR was subjected to a rice-polishing machine (CBS300AS, Satake Co., Hiroshima, Japan) to prepare the bran. The bran (PB) was extracted three times with chloroform/methanol $(2 / 1)$ at $50^{\circ} \mathrm{C}$ for $1 \mathrm{~h}$, and further treated with alpha-amylase (Termamyl, Novozymes, Bagsvaerd, Denmark) at $60^{\circ} \mathrm{C}$ for $18 \mathrm{~h}$ followed by treatment with glycosidase (AMG, Novozymes) at $60^{\circ} \mathrm{C}$ for $4 \mathrm{~h}$. The enzyme-treated PR bran was extracted three times with ethanol and once with acetone, and dried on a fume hood. The nutritional composition of the WR, PR, and the destarched and defatted PR bran (termed as "DB") is shown in Table 1. Particle characterization was also assessed by MICROTRAC (NIKKISO Co., Tokyo, Japan); there was no

Table 1. Composition of WR, PB and DB

\begin{tabular}{lrrr}
\hline \multicolumn{1}{c}{ Component } & WR & PB & DB \\
\hline Water $(\mathrm{g} / 100 \mathrm{~g})$ & 15.6 & 11.8 & 13.9 \\
Protein $(\mathrm{g} / 100 \mathrm{~g})$ & 7.3 & 14.6 & 18.4 \\
Fat $(\mathrm{g} / \mathrm{g} \mathrm{g})$ & 1.5 & 24.8 & 6.1 \\
Ash $(\mathrm{g} / 100 \mathrm{~g})$ & 0.4 & 9.8 & 10.3 \\
Dietary fiber $(\mathrm{g} / 100 \mathrm{~g})$ & $\mathrm{N} . \mathrm{D}$. & 30.5 & 57.6 \\
Starch $(\mathrm{g} / 100 \mathrm{~g})$ & 73.9 & 9.7 & N.D. \\
GABA $(\mathrm{mg} / 100 \mathrm{~g})$ & 3.3 & 61.1 & 0.52 \\
\hline
\end{tabular}

Table 2. Composition of the Test Diet

\begin{tabular}{clccc}
\hline \hline Group & WR $(\mathrm{g})$ & PB $(\mathrm{g})$ & DB $(\mathrm{g})$ & $\begin{array}{c}\text { Total } \\
\text { amount }(\mathrm{g})\end{array}$ \\
\hline WR diet & 2.0 & - & - & 2.0 \\
PB diet & 1.94 & 0.66 & - & 2.60 \\
DB diet & 2.0 & - & 0.35 & 2.35 \\
\hline
\end{tabular}


Table 3. The Amount of Available Carbohydrate, Fiber, Fat and Protein in the Test Diets Given to Rats

\begin{tabular}{ccccccc}
\hline \hline Test group & $\begin{array}{c}\text { Net } \\
\text { intake }(\mathrm{g})\end{array}$ & $\begin{array}{c}\text { Available } \\
\text { carbohydrate }(\mathrm{g})\end{array}$ & $\begin{array}{c}\text { Dietary } \\
\text { fiber }(\mathrm{g})\end{array}$ & Fat $(\mathrm{g})$ & Protein $(\mathrm{g})$ & Water $(\mathrm{g})$ \\
\hline WR diet & 2 & 1.50 & N.D. & 0.04 & 0.15 & 0.31 \\
PB diet & 2.6 & 1.50 & 0.20 & 0.20 & 0.24 & 0.38 \\
DB diet & 2.35 & 1.50 & 0.20 & 0.06 & 0.21 \\
\hline
\end{tabular}

significant difference between $\mathrm{PB}$ and $\mathrm{DB}$ (mode diameter; PB, $296 \mu \mathrm{m}$; DB, $296 \mu \mathrm{m}$, median diameter; PB, $197 \mu \mathrm{m}$; $\mathrm{DB}, 213 \mu \mathrm{m})$. The test diets were prepared by mixing these components as shown in Table 2, and the contents of macronutrients and dietary fiber analyzed are shown in Table 3.

All animal experiments were performed in accordance with institutional guidelines established by the Laboratory Animal Care and Use Committee of Nihon University College of Bioresource Sciences. Male Wistar strain rats (Nippon Bio-Suppl., Tokyo, Japan) at 8 weeks of age were kept with a standard diet (CE-2, CLEA JAPAN Inc., Tokyo, Japan) for $9 \mathrm{~d}$ to acclimate the animal laboratory $\left(22 \pm 2{ }^{\circ} \mathrm{C}\right.$, 8:00 a.m. to $8: 00 \mathrm{p} . \mathrm{m}$. light cycle). These rats were allowed to access freely to the diet and water. Then the rats were trained so called "meal feeding" with AIN-93G (Oriental Yeast Co., Ltd., Tokyo, Japan) for another $9 \mathrm{~d}$ to be able to intake the test diet in a short time (within $15 \mathrm{~min}$ ).

After the fasting for $18 \mathrm{~h}$, rats were given the test diets, WR (2 g), PB (2.6g) or DB (2.35 g) which were containing the equivalent amount of available carbohydrate. Blood was withdrawn from tail vein. Blood glucose concentration was measured by DEXTER-Z II (Bayer Medical Co. Ltd., Leverkusen, Germany), and the plasma insulin was measured by ELISA (Morinaga Institute of Biological Science, Yokohama, Japan). Data are shown as mean \pm S.E. The incremental area under the curve $(I A U C)$ for glucose or insulin concentrations was calculated according to the method described by Wolever and Jenkins. ${ }^{10)}$ The data were analyzed by ANOVA followed by Bonferroni multiple comparison test of means, if the ANOVA indicates the significances.

\section{RESULTS}

Figure 1A shows the blood glucose concentration increased after feeding the WR, PB or DB diet. The rats ate the whole diet given within $15 \mathrm{~min}$. The peak of the increase in blood concentration $(32.4 \mathrm{mg} / \mathrm{dl})$ was observed at $30 \mathrm{~min}$ after the feeding in WR-fed rats, and then the level was declined gradually toward the time point at $120 \mathrm{~min}$. The increase in the blood glucose concentration after feeding the PB was tended to lower than that of rats fed WR at time points 30,90 and $120 \mathrm{~min}$, but significant at $60 \mathrm{~min}$. The changes in the DB-fed rats were almost identical with those in the PB-fed rats. The IAUC for the blood glucose was also significantly smaller in PB $(p=0.048)$ than that in WR. The $I A U C$ of blood glucose for DB-fed rats was also smaller than that in WR ( $p=0.056$, Fig. $2 A)$.

The time-course of the changes in plasma insulin concentrations is shown in Fig. 1B. Plasma insulin concentration was tended to decrease faster in PB or DB-fed rats than WRfed rats. The $I A U C$ analysis for plasma insulin levels also indicate that the total amount of insulin secreted was lower, but

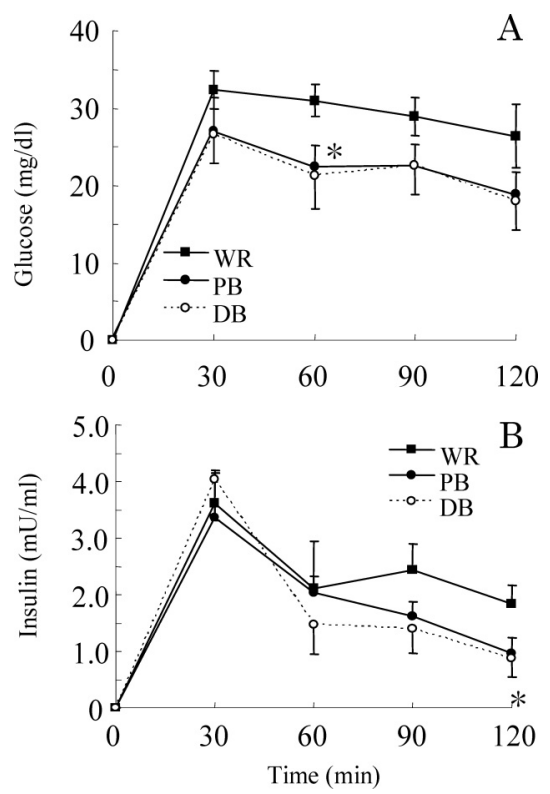

Fig. 1. Changes in Blood Glucose and Plasma Insulin Concentration of Rats Fed either PB, DB or WR

Each value represents the mean \pm S.E. PB, $n=14$; DB, $n=12$; WR, $n=13 * p<0.05$ vs. WR.

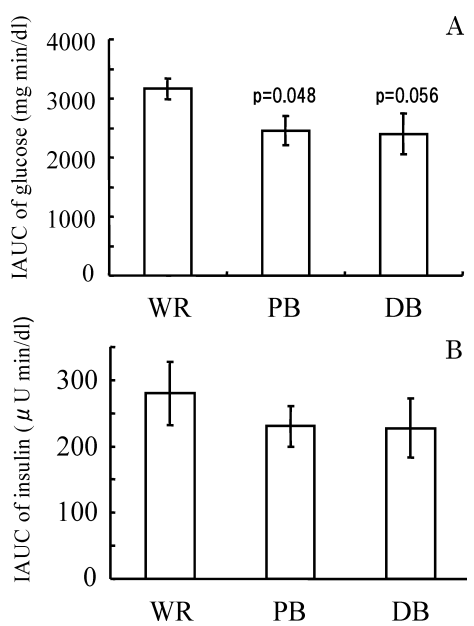

Fig. 2. Incremental Areas Under the Curves for the Changes in Blood Glucose and Plasma Insulin Concentrations of Rats Fed either PB, DB or WR

Each value represents the mean \pm S.E. PB, $n=14$; DE, $n=12$; WR, $n=13 v s$. WR.

not significant in PB or DB-fed rats than that of WR-fed rats (Fig. 2B).

\section{DISCUSSION}

To address the question which constituent(s) is involved in the amelioration of post prandial-hyperglycemia, we pre- 
pared the destarched and defatted PR bran (termed "DB"), and the blood glucose-lowering effects were compared between DB and PB or WR. The test diet made of WR, PB or $\mathrm{DB}$, which contains identical amount of available carbohydrate each other $(1.5 \mathrm{~g})$ was given to rats. Both post-prandial increase in blood glucose concentrations and insulin concentrations were lower in PB diet and DB diet than in WR diet, but there was no obvious difference in the groups between PB and DB. Post-prandial blood glucose concentration is not only influenced by water-soluble fibers such as pectin and guar, ${ }^{11,12)}$ but also by insoluble fiber. ${ }^{13)}$ Thus the insoluble dietary fiber remained in the DB is thought to be the constituent mainly responsible for lowering the post-prandial blood glucose concentration in the rats given DB diet. O'Dea et al. observed that the changes in the blood glucose and insulin responses to BR tended to be smaller than those to $\mathrm{WR},{ }^{14)}$ and that BR was hydrolyzed more slowly than WR in the model system in vitro. ${ }^{15)}$ Insoluble dietary fiber inhibits the glucose absorption and the following increase in the blood glucose concentration. These effects are accomplished by increasing the viscosity of the digests present in the intestinal tract to suppress the diffusion of glucose or by coating the starch and enzyme molecules to inhibit $\alpha$-amylase activity. ${ }^{16)}$ Thus the similar mechanisms might also be involved in the suppression of post-prandial glucose level even in the case of PB or DB diet.

GABA is also known to potentiate the insulin secretion in pancreas. ${ }^{1-4)}$ Although PB contains much more GABA than $\mathrm{DB}$, changes in postprandial blood glucose and insulin concentration in rat fed PB diet were similar to those in rat fed DB diet. These results also suggest that GABA was not the factor to decrease the postprandial blood glucose concentration.

In summary, the blood glucose-lowering effect of PR would be derived from the properties of PR involving substantially higher content of dietary fiber than WR.

The number of diabetic patients is estimated to be in- creased to 220 million in 2015 , and the great increase is supposed in India, China and Japan. ${ }^{17)}$ Because the feeding of PR diet to diabetic model rats ameliorated blood glucose, PAI-1 and lipid peroxide concentrations in comparison with the feeding of WR diet, ${ }^{5)}$ PR may be one of the suitable foods for diabetic patients. Further studies are now under taken to clarify the potential benefit of intake of PB instead of WR in the prevention of diabetic vascular complications.

\section{REFERENCES}

1) Wang C., Ling Z., Pipeleers D., Am. J. Physiol. Endocrinol. Metab., 288, E307-E313 (2005).

2) Wendt A., Birnir B., Buschard K., Gromada J., Salehi A., Sewing S., Rorsman P., Braun M., Diabetes, 53,1038-1045 (2004).

3) Adeghate E., Ponery A. S., Tissue Cell, 34, 1-6 (2002).

4) Gomez R., Asnis N., Tannhauser S. L., Barros H. M., Jpn. J. Pharmacol., 80, 327-331 (1999).

5) Hagiwara H., Seki T., Ariga T., Biosci. Biotechnol. Biochem., 68, $444-447$ (2004).

6) Sobel B. E., Am. J. Med., 113, 12S-22S (2002).

7) Skrha J., Hodinar A., Kvasnicka J., Hilgertova J., Diabet. Med., 13, $800-805$ (1996).

8) Hagiwara H., Kaizu K., Uriu K., Noguchi T., Takagi I., Qie Y. L., Seki T., Ariga T., Thromb. Res., 111, 301-309 (2003).

9) Ito Y., Mizukuchi A., Kise M., Aoto H., Yamamoto S., Yoshihara R., Yokoyama J., J. Med. Invest., 52, (2005) in press.

10) Wolever T. M., Jenkins D. J., Am. J. Clin. Nutr., 43, 167-172 (1986).

11) Wolever T. M., Jenkins D. J., Nineham R., Alberti K. G., Br. J. Nutr, 41, 505-510 (1979).

12) Jenkins D. J., Leeds A. R., Gassull M. A., Cochet B., Alberti G. M., Ann. Intern. Med., 86, 20-23 (1977).

13) Nelso R., Duesberg C., Ford S., Feldman E., Davenport D., Kiernan C., Neal L., JAVMA, 212, 380-386 (1998).

14) O’Dea K., Nestel P. J., Antonoff L., Am. J. Clin. Nutr., 33, 760-765 (1980).

15) O’Dea K., Snow P., Nestel P., Am. J. Clin. Nutr., 34, 1991-1993 (1981).

16) Ou S., Kwok K., Li Y., Fu L., J. Agric. Food Chem., 49, 1026-1029 (2001).

17) Zimmet P., Alberti K. G., Shaw J., Nature (London), 414, 782-787 (2001). 